\title{
WestVirginiaUniversity
}

THE RESEARCH REPOSITORY @ WVU

Graduate Theses, Dissertations, and Problem Reports

2007

\section{Parenting factors related to asthma and anxiety in children}

\author{
Abby H. Friedman \\ West Virginia University
}

Follow this and additional works at: https://researchrepository.wvu.edu/etd

\section{Recommended Citation}

Friedman, Abby H., "Parenting factors related to asthma and anxiety in children" (2007). Graduate Theses, Dissertations, and Problem Reports. 2570.

https://researchrepository.wvu.edu/etd/2570

This Dissertation is protected by copyright and/or related rights. It has been brought to you by the The Research Repository @ WVU with permission from the rights-holder(s). You are free to use this Dissertation in any way that is permitted by the copyright and related rights legislation that applies to your use. For other uses you must obtain permission from the rights-holder(s) directly, unless additional rights are indicated by a Creative Commons license in the record and/ or on the work itself. This Dissertation has been accepted for inclusion in WVU Graduate Theses, Dissertations, and Problem Reports collection by an authorized administrator of The Research Repository @ WVU.

For more information, please contact researchrepository@mail.wvu.edu. 
Parenting Factors Related to Asthma and Anxiety in Children

Abby H. Friedman, M.S.

\author{
Dissertation submitted to the \\ Eberly College of Arts and Sciences \\ at West Virginia University \\ in partial fulfillment of the requirements \\ for the degree of \\ Doctor of Philosophy \\ in \\ Psychology \\ Tracy L. Morris, Ph.D., Chair \\ Mary Beth Hogan, M.D. \\ Kevin T. Larkin, Ph.D. \\ Cheryl B. McNeil, Ph.D. \\ Julie H. Patrick, Ph.D. \\ Department of Psychology
}

Morgantown, West Virginia

2007 


\author{
Abstract \\ Parenting Factors Related to Asthma and Anxiety in Children \\ Abby Friedman, M.S.
}

The present study examined the association between parenting style and anxiety in children with asthma. Participants included 60 children with asthma and 60 controls, aged 9-12 years. At least one of the children's parents participated. The children and their parents completed self-report measures of anxiety and depressive symptoms. Children reported on their parent's style of parenting, while parent's reported on parent-child relationship quality. Parents and physicians completed asthma severity reports. Results partially replicated previous findings. A Multivariate Analysis of Variance (MANOVA) demonstrated that children with asthma obtained significantly higher scores than controls on the Multidimensional Anxiety Scale for Children (MASC). Further, a multiple regression analysis showed that significant beta values emerged for parenting style on MASC scores. A chi-square demonstrated no differences between asthma and control groups on four parenting styles: optimal, neglectful, affectionate restraint, and affectionless control. A MANOVA showed that children with asthma and controls did not differ significantly on the Involvement, Communication, and Autonomy subscales of the PCRI. Implications of this study, including areas to target for prevention and early intervention, are discussed. 


\section{Acknowledgements}

I would like to express sincere appreciation and gratitude to my committee chair and advisor, Dr. Tracy Morris. This project and my academic career would not have been possible without her guidance, dedication, and support. I would also like to thank my dissertation committee members, Dr. Mary Beth Hogan, Dr. Cheryl McNeil, Dr. Kevin Larkin, and Dr. Julie Patrick, for their scholarly contributions to this work. I could not have completed this project without the support and love of my best friend and fiancé, Dr. Justin Harris. Finally, I am indebted to my parents, Margaret and Steven Friedman. They have inspired, encouraged, supported, and loved me unconditionally. 


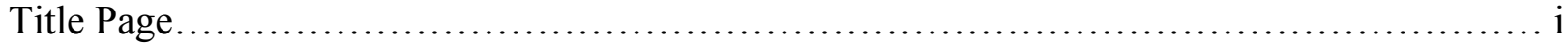

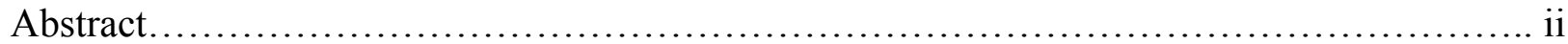

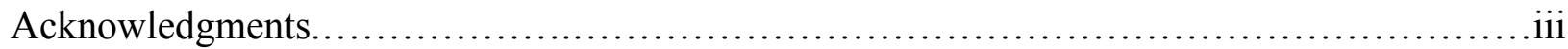

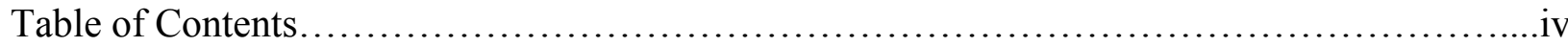

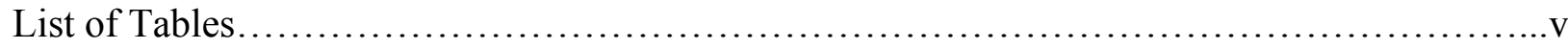

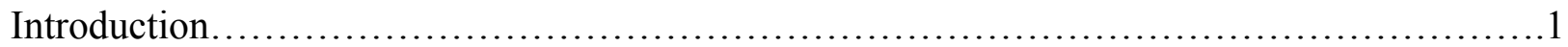

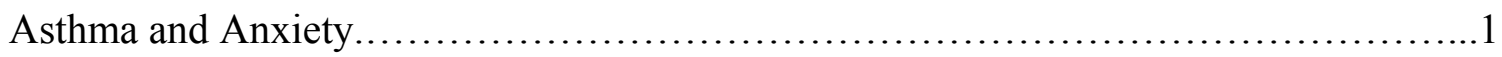

Theories Explaining the Association between Asthma and Anxiety ....................6

Parenting Style and Anxiety ........................................................

Limitations of the Parenting Style and Anxiety Literature..............................11

Parenting Style and Asthma..........................................................12

Limitations of the Parenting Style and Asthma Literature...............................14

Statement of the Problem and Hypotheses............................................ 15

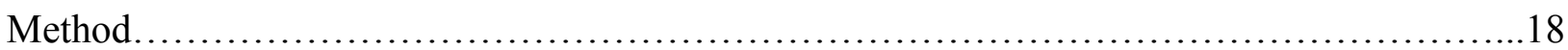

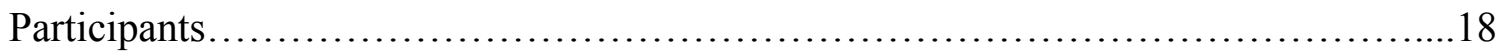

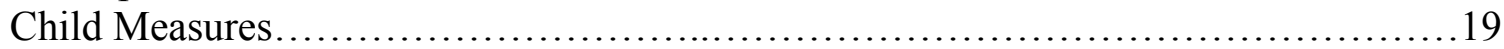

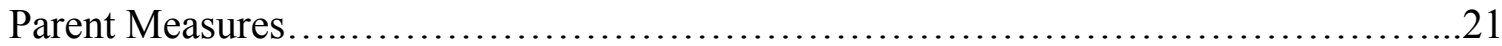

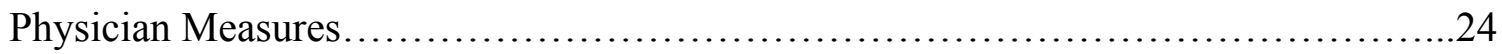

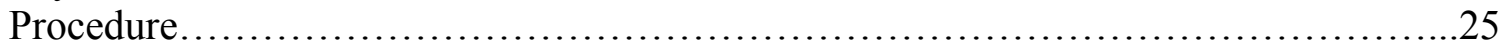

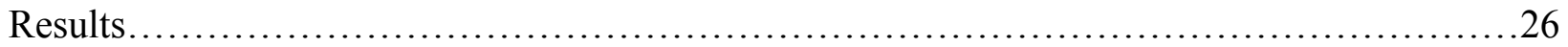

Parenting Style and Group Status...............................................26

Parent-Child Relationship and Group Status .......................................26

Anxiety and Depression Scores By Group .........................................27

Parenting Style, Group Status, Anxiety, and Depression Scores .......................28

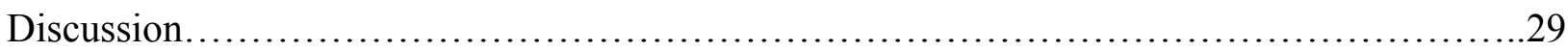

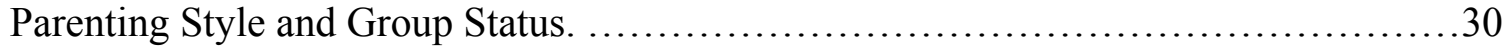

Parent-Child Relationship and Group Status ......................................30

Anxiety and Depression Scores By Group.............................................31

Parenting Style, Group Status, Anxiety, and Depression Scores .........................33

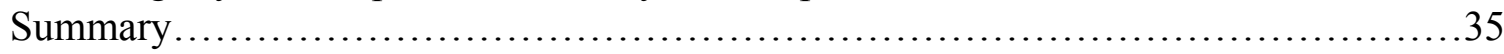

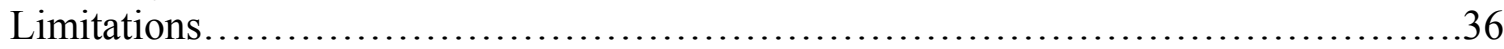

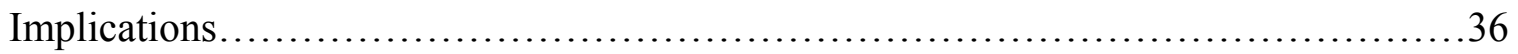

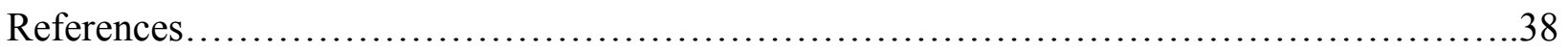




\section{List of Tables}

Table 1. PCRI and PBI Scores by Group.............................................52

Table 2. Mean Asthma Severity Scores and Mean Anxiety/Depression Scores by Group........53

Table 3. Multiple Regression of Parenting Style, Parental Anxiety/Depression Scores, Group Status, and Asthma Severity on MASC Scores.........................................54

Table 4. Correlations of Parenting Style, Parental Anxiety/Depression Scores, Group Status, and

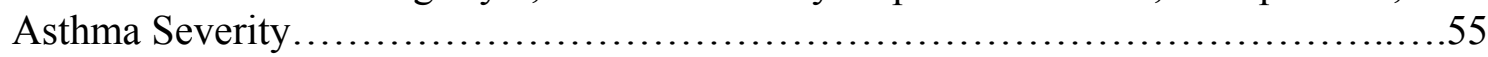


Parenting Factors Related to Asthma and Anxiety in Children

Asthma is one of the most common chronic illnesses currently affecting children (National Center for Health Statistics [NCHS], 2003; Newacheck \& Taylor, 1992). Asthma affects approximately $5 \%$ to $12 \%$ of children under the age of 18 ( Akinbami, Schoendorf, \& Parker, 2003; NCHS, 2002). The prevalence of asthma has increased approximately 4\% per year since 1980 (Akinbami \& Schoendorf, 2002). This condition is more common in boys than girls and affects more African American and Latino children than Caucasian children (Evans, 1992; NCHS, 2002). Approximately 50\% to $90 \%$ of children with asthma exhibit symptoms prior to five years of age (e.g., Martinez \& Wright, 1995). Asthma is characterized by inflammation or swelling of the airway and overproduction of mucous which may occur without warning, in response to allergens, viruses, and bacteria, or following exercise (Jarjour \& Kelly, 2002; Macdowell \& Bacharier, 2005). The National Institutes of Health (NIH) guidelines for asthma diagnosis dictate that to make a diagnosis of asthma a physician must: (a) identify episodes in which airflow is obstructed, (b) determine that restriction in airflow is reversible and, (c) exclude alternative diagnoses (National Institutes of Health [NIH], 1997). Asthma often is comorbid with psychological illnesses, with concomitant increases in functional impairment, health care costs, peer relationship problems, and academic difficulties (Garralda, Bowman, \& Mandalia, 1999; Sawyer, Spurrier, Kennedy, \& Martin, 2001; Vila et al., 2003; Wamboldt, Fritz, Mansell, McQuaid, \& Klein, 1998). Anxiety disorders are one of the most common psychological disorders comorbid with asthma in children and adolescents (Katon, Richardson, Lozano, \& McCauley, 2004).

Asthma and Anxiety 
Several studies have demonstrated an association between asthma and anxiety disorders in children and adolescents. Butz and Alexander (1993) assessed anxiety symptoms in 155 children with asthma and their mothers. Participants were 7-12 years of age and had visited the emergency department for an asthma attack within the past year. Home visits were conducted at two points during the eight-week period following the emergency department visit. The StateTrait Anxiety Inventory for Children (STAIC; Spielberger, Edwards, Lushene, Vagg, \& Jacobs, 1973) and the State-Trait Anxiety Inventory Form Y (STAI; Spielberger, Gorusch, Lushene, Vagg, \& Jacobs, 1983) were administered to the children and their mothers respectively at the first home-visit. The mothers also completed demographic and illness history questionnaires at that time. During the follow-up visit, participants' mothers reported on the occurrence of asthma symptoms, hospitalizations, and activity limitations for the previous 8-week period.

Mothers (trait, $M=39.01, S D=10.13$; state, $M=38.61, S D=10.43$ ) scored significantly higher than their children (trait, $M=37.39, S D=6.10$; state, $M=29.97, S D=5.32$ ) on the trait and state subscales of the STAI, and children's anxiety was significantly associated with a moderate number of parent-reported asthma attacks $\left(\mathrm{r}^{2}=0.15, p<.05\right)$. Mothers of children with asthma-onset prior to age one scored higher on trait anxiety than mothers of children with later asthma-onset (36.1\% vs. $11.1 \%)$. The authors concluded that maternal and child anxiety is highest immediately prior to an asthma attack and may be a learned response to anxietyprovoking stimuli associated with asthma attacks (e.g., difficulty breathing).

Gupta, Mitchell, Gluffre, and Crawford (2000) also used the STAI (Speilberger et al., 1973) to assess anxiety symptoms in mothers of 40 children with asthma, aged 6-17 years. Children with asthma were compared to 39 children with congenital heart disease on the Fear Survey Schedule for Children - Revised (FSSC-R Ollendick, 1978), the Revised Children's 
Manifest Anxiety Scale (RCMAS; Reynolds \& Richmond, 1985), and the Child Behavior Checklist (CBCL; Achenbach \& Edelbrock, 1983). Diagnoses and disease severity were reported by the physician. Children with asthma and children with congenital heart disease did not score significantly different from one another on the FSSC-R, RCMAS, or CBCL. Asthmatic children did score significantly higher than children with heart disease on the Medical Fears Subscale of the FSSC-R $(\mathrm{F}=4.54, p<.05)$. Higher scores on the child-completed measures were associated with higher maternal scores on the STAI for both groups $(\mathrm{r}=.705, p<.0001)$. Greater severity ratings were significantly associated with higher anxiety scores $(\mathrm{r}=.246, p<.001)$. The researchers hypothesized that maternal anxiety and familial factors (e.g., stress) played a role in the elevated anxiety symptom scores of children in both groups.

Ortega et al. (2003) examined the presence of asthma and various psychological disorders in a community sample of 1,890 Puerto Rican children. A questionnaire developed for the study was used to assess for a history of asthma diagnosis, asthma attacks, or hospitalizations due to asthma. The Diagnostic Interview Schedule for Children (DISC; Costello, Edelbrock, Kalas, \& Duncan, 1984) and the History of Family Psychopathology Questionnaire (Lish, Weissman, Adams, Hoven, \& Bird, 1995) were used to assess for anxiety symptoms and anxiety disorders. Of the 1,890 children surveyed, $32 \%$ reported having physician-diagnosed asthma, $22 \%$ reported a history of asthma attacks, and $17 \%$ reported a history of hospitalization(s) for asthma. Twenty percent of the children diagnosed with asthma met criteria for a psychiatric disorder.. Anxiety disorders $(9 \%)$ and disruptive behavioral disorders $(15 \%)$ were the most common psychological diagnoses associated with asthma. Ortega, McQuaid, Canino, Goodman, and Fritz (2004) further analyzed these data to examine the association between anxiety disorders and asthma. These researchers found that children with histories of asthma diagnoses reported experiencing 
significantly more physiological symptoms of generalized anxiety disorder and separation anxiety disorder $\left(x^{2}=5.13, p<.05\right)$. It is important to note that compared to other children, Puerto Rican children have been shown to have higher rates of asthma (e.g., Homa, Mannino, \& Lara, 2000). Some studies have proposed that Puerta Rican children have different inflammatory responses to asthma which are explained by interactions between genes and the environment (Colp, Pappas, Moran, \& Lieberman, 1993; Colp et al., 1990).

Vila, Nollet-Clemencon, De Blic, Mouren-Simeoni, and Scheinmann (1998) assessed the presence of psychological conditions in 92 children with asthma aged 8 to 17 years. Participants were recruited from an outpatient clinic in France and asthma diagnoses and severity ratings were provided by the children's physician. The participants' parents completed the CBCL (Achenbach \& Edelbrock, 1983) and the Conner’s Parent Rating Scale (CPRS; Goyette, Conners, \& Ulrich, 1978), while each child completed the STAIC (Spielberger et al., 1973), the Children's Depression Inventory (CDI; Kovacs, 1985), and the Self-Esteem Inventory (SEI; Coopersmith, 1981). The researchers also interviewed participants with the Revised Schedule for Affective Disorders and Schizophrenia for School-Aged Children (KSADS-R; Chambers et al., 1985). Results demonstrated parent-rated behavior problems were significantly associated with asthma severity (i.e., mild asthma $N=12 ; M=44.6, S D=11.2$, moderate and severe asthma $N=$ $80 ; M=54.6, S D=11.3)$. Anxiety disorders were more prevalent among children with moderate and severe asthma (36\%) than children in the general population.

Wamboldt, Fritz, et al. (1998) attempted to clarify the association between asthma and psychopathology, using a sample of 337 children and adolescents in a multi-site study. Participants mean ages included 11.1 years at the New Hampshire site, 10.5 years in Texas, and 14.2 years in Colorado. Asthma diagnoses and severity ratings were provided by the child's 
physician. Participants completed the RCMAS (Reynolds \& Richmond, 1985), CBCL

(Achenbach \& Edelbrock, 1983), Asthma Functional Morbidity Measure developed for the study (i.e., an assessment of asthma related functional limitations), and the Weinberger Adjustment Inventory (i.e., a measure of social and emotional adjustment; Weinberger, 1991). The participants also underwent IQ testing and their parents completed the Pennebaker Inventory of Linguid Languidness (PILL; Pennebaker, 1982) to assess frequency of health-related behaviors. Wamboldt, Fritz, et al. (1998) found a significant association between asthma severity and internalizing symptom scores on the CBCL for parent-reports only $(F=3.68, p<.01)$. The researchers hypothesized that the parents' reports were influenced by their own symptoms of anxiety in relation to their child's asthma.

Bussing, Burket, and Kelleher (1996) used structured diagnostic interviews to assess anxiety disorders in children with asthma and familial influences on these comorbid conditions. These researchers used the Schedule for Affective Disorders and Schizophrenia for School-Age Children (K-SADS; Puig-Antich \& Ryan, 1986) and the Index of Family Relations (IFR; Hudson, 1990) to interview 37 asthmatic and 25 healthy children aged 7 to 17 years. Results demonstrated that asthmatic children were twice as likely as healthy controls to be diagnosed with anxiety disorders $(p<.05)$. Of the children in the asthma group, $44 \%$ had family members with a history of psychiatric diagnoses and $24 \%$ of their parents reported experiencing high levels of stress.

Craske, Poulton, Taso, and Plotkin (2001) examined the development of panic disorder in a group of 992 adults aged 18 to 21 years, who had been assessed at 2-year intervals since their third year of life. Participants were interviewed with the Diagnostic Interview Schedule (DIS; Robins, Helzer, Croughan, \& Ratcliff, 1981) to determine psychological diagnoses and 
participants' mothers reported the child's and family's history of asthma and other medical or psychological illnesses. Allergy testing was also conducted. Results showed that a diagnosis of asthma prior to the age of 18 predicted the later development of panic disorder and agoraphobia. Goodwin, Pine, and Hoven (2003) examined the association between asthma and panic attacks in a nationwide sample of 1285 children aged 9 to 17 years. The children were interviewed using the DISC (Costello et al., 1984) and one parent completed questionnaires on frequency and severity of the child's asthma attacks, family history of psychological and medical illnesses, and demographic variables. A chi-square classification tree showed that diagnoses of asthma increased the likelihood of panic attacks and asthma severity predicted the strength of the association between asthma and panic attacks. Asthma severity was the second splitting variable found in the classification tree. The tree used correctly classified 41 out of 66 individuals with panic disorder and 241 out of 298 controls.

\section{Theories Explaining the Association between Asthma and Anxiety}

Some theories have been proposed to explain the association between asthma and anxiety. Literature attempting to explain the association between allergies and anxiety is limited. Two types of theories have been proposed to elucidate the association between anxiety and allergies, which include biological and cognitive-behavioral theories. It is important to note that these theories have limited empirical support, warranting further research. Systematic replication and specific investigation is required to provide supporting evidence for these theories. One biological theory is that allergies and anxiety disorders have specific structural and neurochemical processes in common (Kagan, Reznick, \& Snidman, 1987; Kagan, Reznick \& Snidman, 1988; Arcus, 1994). A second biological theory is that anxiety and allergic disorders are genetically linked (Wamboldt et al., 2000; Wamboldt, Schmitz, \& Mrazek,1998). 
Cognitive-behavioral theories emphasize the role of learning in the development of comorbid allergies and anxiety disorders. One cognitive-behavioral theory posits that classical conditioning explains the association between anxiety and allergies, in which children and adolescents who experience symptoms of an allergic reaction (i.e., unconditioned stimulus) fear the recurrence of these symptoms. The child then experiences feelings of anxiety and fear (i.e., conditioned response) in relation to symptoms associated with an allergic reaction (i.e., conditioned stimulus; Carr, 1997; Feldman, Giardino, \& Lehrer, 2000; Reznick et al., 1986).

Another cognitive-behavioral explanation of comorbid anxiety and allergies involves learning and parental modeling. This theory proposes that parents model maladaptive coping skills and exhibit overprotective behavior to reduce feelings of fear (Bender et al., 2000; Mrazek, Schuman, \& Klinnert, 1998). The child then learns maladaptive coping skills and develops anxious responding to stimuli. Previous research has demonstrated a link between parenting style and asthma, and parenting style and anxiety. Very little research, however, has been conducted to examine the association between parenting style and comorbid anxiety and asthma.

\section{Parenting Style and Anxiety}

Parenting style has been defined as a set of attitudes, goals, and parenting practices that create an emotional environment through which the parent and child interact (Darling \& Steinberg, 1993). Parenting style has been shown to play a role in the development and maintenance of anxiety disorders. Siqueland, Kendall, and Steinberg (1996) examined levels of parental warmth and control in parents of children with anxiety disorders and controls. The Anxiety Disorders Interview Schedule (ADIS; Silverman \& Nelles, 1988) was used to interview both the child and their parent and the child's teacher and parent also completed the CBCL (Achenbach \& Edelbrock, 1983). Parents indicated the degree of conflict experienced with their 
spouse and child on the Issues Checklist (IC; Robin \& Weiss, 1980) and the O'Leary-Porter Scale-Revision (OPS-R; Porter \& O'Leary, 1980). The children completed the Children's Report of Parenting Behavior Inventory (CRPBI; Schluderman \& Schluderman, 1970), RCMAS (Reynolds \& Richmond, 1985), Children's Depression Inventory (Kovacs, 1985), and the IC (Robin \& Weiss, 1980). Participants and their parent(s) also engaged in interaction tasks which involved discussing topics on which they disagreed. Results demonstrated that anxious children were less likely than controls to be granted autonomy during family discussions (effect size $=$ .29 ) and reported that their parents were less accepting (effect size $=.44)$.

Silove, Parker, Hadzi-Pavlovic, Manicavasagar, and Blaszcynski (1991) examined differences in parenting style between specific anxiety disorders. Adult participants reported their parent's style and quality of parenting on the Parental Bonding Instrument (PBI; Parker, Tupling, \& Brown, 1979). The anxiety group consisted of 80 adult patients diagnosed with generalized anxiety disorder or panic disorder and age and sex-matched controls. Results demonstrated that individuals with generalized anxiety disorder or panic disorder were more likely than controls to have experienced overprotective parenting. Participants with panic disorder, however, were more likely than participants with generalized anxiety disorder and controls to report low levels of parental warmth.

Hernandez-Guzman and Sanchez-Sosa (1996) evaluated the contribution of parenting style to the development of anxiety disorders. A large sample of 3,432 Mexican-American adolescents aged 15 to 18 years provided retrospective reports of parenting style and practices during their early childhood. Participants completed the Health, Lifestyles, and Behavior Inventory developed for the study. This measure was used to assess psychological functioning, family interactions, and parenting style. Parent-child interaction was defined as the degree to 
which the following occurred: affection, support, conversation, parental interest in what their child says, relationship quality, intimacy, and negative comments. Anxiety symptoms were coded according to cognitive, somatic, and motoric reactions. Cognitive, somatic, and motoric symptoms of anxiety were significantly correlated with mother-child (cognitive, $r=-.26, p<$ .001 ; somatic, $r=-.22, p<.001$; motoric, $r=-.19, p<.001)$ and father-child interactions (cognitive, $r=-.22, p<.001$; somatic, $r=-.17, p<.001$; motoric, $r=-.20, p<.001$ ).

Dumas, Serketich, and LaFreniere (1995) examined controlling behaviors in 126 motherchild dyads. The preschoolers were categorized as socially competent, aggressive, or anxious, according to teacher's ratings on the Preschool Socioaffective Profile (PSP; LaFreniere, Dumas, Capuano, \& Dubeau, 1992). Mother-child dyads engaged in observed interaction tasks on a grocery store game, involving planning out and buying specific groceries according to rules explained by the research assistant. The dyads were observed and behaviors were coded for positive interactions, coercive interactions, negative affect, controlling commands or actions, compliance, and noncompliance. Anxious children $(F(2,123)=4.72, p<.01)$ and their mothers $(\mathrm{t}(41)=-2.59, p<.05)$ were more likely to use controlling and coercive behavior. The children in the sample complied with the majority of their mother's requests when their mother was controlling the exchange; however, some group differences were noted. Anxious children were less likely than other children to comply with their mother's covercive requests $(F(2,120)=$ $5.09, p<.01$ ) and compliance was more likely to occur with aversive than positive commands. Mothers of anxious children were more likely than the other mothers to use coercive and aversive commands, and often refused to comply with their children's aversive and coercive commands. 
Greco and Morris (2002) investigated observed and reported parenting style in fathers of socially anxious children. Social anxiety was assessed using the Social Phobia and Anxiety Inventory for Children (SPAI-C; Beidel, Turner, \& Morris, 1995). Participants were grouped as high social anxiety $(N=22)$ and low social anxiety $(N=26)$. Children also completed the Multidimensional Anxiety Scale for Children (MASC; March, Parker, Sullivan, Stallings, \& Conners, 1997), CDI (Kovacs, 1985), and Parental Bonding Instrument (PBI; Parker, Tupling, \& Brown, 1979). Father-child dyads were observed while engaging in an interaction task. Paternal and child overprotecting and rejecting behaviors were coded according to the following: criticisms, praise, lack of response, commands, and physical control. Child behaviors were also coded for acceptance and rejection of commands, and requesting support. Results demonstrated a significant difference between groups in terms of paternal behavior $(F(5,38)=4.61, \mathrm{p}=.01)$. Fathers of highly socially anxious children exhibited more physical control $(M=12.5$, S.D. $=$ 5.0) than fathers of children in the low social anxiety group $(M=7.0, S . D .=3.8)$.

Hudson and Rapee (2002) observed parent-child interactions between 37 anxious and 20 non-anxious children aged 7 to 16 years, their siblings, and one parent. The dyads were observed while engaging in a puzzle completion task together. Parent behaviors were coded according to involvement, unsolicited help, posture, focus, and amount of physical involvement with the puzzle. Children completed the RCMAS (Reynolds \& Richmond, 1985) and the CDI (Kovacs, 1985). Parents completed the Beck Anxiety Inventory (BAI: Beck, Epstein, Brown, \& Steer, 1988), the Beck Depression Inventory (BDI; Beck, Ward, Mendelsohn, Mock, \& Erbaugh, 1961), and the CBCL (Achenbach \& Edelbrock, 1983). Parents of anxious children and their siblings were more intrusive and overinvolved $(t(55)=2.78, p<.05)$ in the puzzle task than parents of control children. Although there were differences in levels of involvement between 
groups, there were no significant differences in levels of parental involvement between anxious children and their siblings.

Rapee and Melville (1997) also examined the influence of overprotective and controlling parenting on social phobia and panic disorder in adults. The sample consisted of 38 adults with social phobia, 26 with panic disorder, 25 controls, and their mothers. Participants completed a measure of parenting behaviors developed for the study and the Overprotection subscale on the PBI (Parker et al., 1979). Individuals with social phobia rated their mothers as significantly more overcontrolling than controls $(F(2,84)=3.59, p<.05)$. Participants from both clinical groups $(F(2,86)=6.62, p<.05)$, and their mothers $(F(2,50)=4.04, p<.05)$, were significantly more likely than controls to report lower levels of socialization. These individuals also endorsed having significantly fewer friends than controls.

Limitations of the Parenting Style and Anxiety Literature. Despite differences in methodology, these studies have demonstrated that parenting style is associated with the development and maintenance of anxiety disorders. These studies, however, suffer from several limitations. Very few of the reviewed studies have used child self-report to assess parenting style. Child self-report often reveals information that is not found using other methods of assessment. Silove et al. (1991) and Hernandez-Guzman and Sanchez-Sosa (1996) used selfreport measures of parenting style, however, these reports were retrospective. Retrospective reports may be limited by imprecise recall of parenting behaviors and symptom onset. Although behavioral observations are an important aspect of assessment, the reviewed studies conducted behavioral observations within the context of analogue tasks over short periods of time. This may reduce the likelihood of identifying patterns in the parent-child relationship and style of parenting that may contribute to the development of anxiety. 
Psychometric properties were not reported for many of the measures used to assess anxiety and parenting style. Hernandez-Guzman and Sanchez-Sosa (1996) assessed both psychological functioning and parenting style, using a measure designed for the study. Dumas et al. (1995) and Hudson and Rapee (2002) determined parenting style, using observational tasks developed for the studies. Observational tasks can provide important information that may not be available through other assessment means. These methods, however, may lack external validity when used as the only measure of a construct (Ginsburg, Siqueland, Masia-Warner, \& Hedtke, 2004). Observational methods can also be problematic because the operational definitions of parenting behaviors and style may differ between coding methods. These differences may play a role in determining study results (Masia \& Morris, 1998).

\section{Parenting Style and Asthma}

Literature in the area of parenting style and asthma is more limited than research in the area of parenting style and anxiety. Weil et al. (1999) examined the influence of child and parent psychological functioning, family functioning, and parenting style on asthma morbidity. Participants included 1528 children with asthma aged 4 to 9 years and their parent(s). Parents completed the CBCL (Achenbach \& Edelbrock, 1983), Brief Symptom Inventory (BSI; Derogatis \& Melisaratros, 1983), Block Child Rearing Practices Report (Rickel \& Biasatti, 1982), Social Support Questionnaire developed for the study, and the Life Events Scale (Dohrenwend, Krasnoff, Askenasay, \& Dohrenwend, 1978). Parents also answered questions about the severity of their child's asthma, including frequency of hospital and doctor visits for asthma and level of functional impairment. Parent psychopathology was one of the most significant variables contributing to asthma morbidity $(r=-.12, p<.01)$. Children whose parents scored above the clinical cutoff score on the BSI were more than twice as likely to be 
hospitalized for their asthma. Children who scored above clinical cutoff scores on the CBCL were more likely to experience asthma related functional impairments. Nurturing and restrictive styles of parenting were not significantly correlated with asthma morbidity.

Klinnert, Mrazek, and Mrazek (1994) assessed the effects of parenting stress and parenting style on the development of asthma. The sample consisted of 150 women who were pregnant with the target child at the time of the study. Interviews were conducted during the first and third trimesters and three weeks after the child was born. Participants were followed for three years. The mothers completed the Family Inventory of Life Events (FILE; McCubbin, Patterson, \& Wilson, 1983), the Parenting Risk Scale (PRS; Mrazek, Klinnert, Mrazek, \& Macey, 1991), and the Quality of Relationship Scale (QRS; Klinnert, Mrazek, \& Mrazek, 1992). The researchers conducted a home visit three weeks after the infant was born and interviewed mothers about stress and coping. Problematic parenting was defined via the PRS which consisted of the interviewer's global rating of the mother's coping skills, mood, ability to regulate her baby, and level of partner support. The PRS was also used to measure such parenting practices in follow-up studies by Mrazek et al. (1999), and Klinnert et al. (2001). Mothers and their infants also were observed to assess the mother's interactional style with her infant. Significantly more mothers of children who developed asthma by age 3 were rated as having problematic parenting behavior $\left(X^{2}(1)=5.98, p<.01\right)$. The combination of problematic parenting style and stress was found to predict asthma onset, with $25 \%$ of children from high-stress/problematic parenting families developing asthma compared to $5 \%$ of children from low-stress/adequate parenting families.

In a follow-up study using the same sample of mother-infant dyads, Mrazek et al. (1999) evaluated the contribution of different risk factors to asthma onset. Risk factors included number 
of infections before one year of age, blood testing, parenting difficulties, eczema, breast-feeding, gender, genetic risk, socioeconomic status, daycare, and smoking. Parenting difficulties were defined as maternal depression, quality of marital relationship, history of psychological illness, emotional involvement with the child, and quality of parenting behaviors. Out of the eleven variables tested, only frequent infection ( $o r=5.4, p<.01)$, blood levels $(o r=4.6, p<.01)$, parenting difficulties (or $=3.9, p<.05)$, and eczema $(o r=3.1, p<.05)$ were significantly associated with asthma onset. Taken together, the four risk factors accounted for $55 \%$ of the variance in asthma onset, while parenting difficulties alone accounted for 6\%. Parents who were emotionally involved with their child and exhibited high quality parenting behaviors were found to have infants who had a $2 \%$ risk of developing asthma.

Klinnert et al. (2001) reviewed the medical records of 145 of the 150 original participants from Mrazek et al. (1999) to determine the prevalence of asthma diagnoses. Forty of these children were diagnosed with asthma between the ages of six and eight years. Of the variables found to predict asthma during the initial assessment study, number of infections, blood levels, and parenting difficulties, were significantly associated with asthma diagnoses at ages 6 to 8 . Out of the original sample, 103 mothers participated in interviews to assess their psychological functioning and completed the CBCL (Achenbach \& Edelbrock, 1983) for their children. Higher levels of parenting difficulties at the original visit were significantly associated with maternal reports of depressive symptoms and their children's internalizing symptoms on the CBCL.

Limitations of the Parenting Style and Asthma Literature. The available research on parenting style and asthma is limited. Despite differences in methodology, sample populations, and study designs, the available literature has shown a consistent association between 
problematic parenting style and asthma. These studies, however, suffer from methodological limitations. All of the reviewed studies exclusively used parent self-report to assess parenting style and parenting behaviors. Self-report measures provide valuable information that often cannot be observed or easily measured (e.g., worries, fears), however, the self-report of behavior has been shown to be biased under certain circumstances (Ederer, 2004). Self-report biases include presenting oneself in a socially desirable fashion and providing answers that reduce the likelihood of criticism (Steele, Phipps, \& Srivastava, 1999). Furthermore, the use of only one type of measure to assess a construct is problematic as it may limit the validity of conclusions that can be drawn. In addition, parenting style is a multidimensional construct in which the child is highly involved, making their report especially important.

None of the reviewed studies controlled for asthma severity. Children with moderate to severe asthma have been shown to have higher levels of psychological problems than children with milder forms of asthma (e.g., Bussing et al., 1996; Goodwin et al., 2003). This also has been shown to occur in parents of children with more severe asthma (e.g., Wamboldt, Fritz et al., 1998). Controlling for asthma severity also reduces the likelihood that this variable may confound results. Of the reviewed studies, Klinnert et al. (2001) was the only one to use a method other than parent self-report to determine asthma presence. Parent-reports have been shown to underestimate asthma prevalence and severity (Roberts, 2003). Multiple reporters, including physicians, parents, and children, increases the validity of asthma classification.

\section{Statement of the Problem and Hypotheses}

The purpose of the present study is to investigate the association between parenting style and anxiety in children with asthma. Previous literature has demonstrated that parenting style plays a role in the development and maintenance of both asthma and anxiety (e.g., Klinnert et 
al., 1994; Silove et al., 1991). Research also has shown that asthma and anxiety are significantly related to one another and often are comorbid in children and adolescents (e.g., Goodwin et al., 2003). Parenting style has not been studied in terms of its association with comorbid anxiety and asthma. Children and adolescents with comorbid anxiety disorders and medical conditions have been shown to be at a higher risk of developing mental health problems in adulthood, have poorer health outcomes, and experience more limitations in school and peer-related activities (Dorn et al., 2003; Engstrom, 1999).

Previous studies have demonstrated an association between asthma and anxiety in general, however, few studies have examined specific anxiety disorders. This study includes measures of general anxiety and social anxiety. Asthma symptoms often impact social behavior, especially in children (e.g., Milton, Whitehead, Holland, \& Hamilton, 2004). For example, children with asthma often are unable to play or engage in physical activities because of their symptoms. Asthma symptoms, such as coughing, choking, and breathing difficulties, may call attention to the child, possibly increasing their anxiety. Further, anxiety and depression are frequently comorbid in both children and adults. This comorbidity often results in more functional, academic, and social impairment than either disorder alone, making it necessary to target depression when studying anxiety (e.g., Rapaport, 2001; Seligman \& Ollendick, 1998). Thus, the current study includes measures of parental and child depression.

Knowledge of how parenting style contributes to the comorbidity of anxiety and allergies in children and adolescents is especially important because these disorders generally begin during the period between infancy and late adolescence. Comorbid anxiety and allergies may have profound effects on daily functioning (e.g., going to school) and developmental milestones (e.g., making friends). Furthermore, the association between parenting style and these conditions 
needs to be understood in terms of the development of these disorders. Most importantly this research is necessary for early identification of at risk children and to develop suitable intervention and prevention programs.

The hypotheses of the present study are the following:

1. Based on previous research (e.g., Klinnert et al., 1994; Mrazek et al., 1999), parenting style will differ between asthma and control children. Parents of children with asthma are expected to be more likely to engage in overprotection than parents of controls.

2. Parent-child relationship has not previously been investigated in children with asthma. Thus, the difference between parent-child relationship of children with asthma and controls will be explored.

3. Consistent with prior research (e.g. Ortega et al., 2003; Vila et al., 1998; Butz \& Alexander, 1993), children's scores on the MASC, SPAI-C, and CDI were expected to differ significantly between asthma and control groups, with higher scores reported in the asthma group.

4. Previous studies have demonstrated that parental psychopathology is higher among children with asthma compared to controls (e.g., Weil et al., 1999; Bussing et al., 1996). Thus, it is expected that parent's scores on the BAI, SPAI, and BDI-II, will differ significantly between asthma and control groups, with higher scores reported in the asthma group.

5. Previous research has demonstrated a significant association between asthma and anxiety (e.g., Ortega et al., 2004) and between parenting and asthma (e.g., Mrazek et al., 1994). Thus, it is expected that parenting style, group status, 
asthma severity and parent's anxiety/depression scores will predict children's scores on anxiety and depression measures. Specifically, it is expected that children with asthma will be more likely to have parents with an overprotective style of parenting. Further, it is expected that children with asthma will obtain higher scores on measures of anxiety and depression.

Method

\section{Participants}

Participants included 60 children aged 8 to 12 years with mild to severe asthma, and at least one of their parents. A control group, matched for age and gender, consisted of 60 children who had no known asthma or allergic diseases, and at least one of their parents. This included children visiting for well-child checks, sports related physicals, and acute injury or illnesses. Children were excluded from participation in either group if they or their parent(s) were not English speakers or had cognitive disabilities that would interfere with study participation. No potential participants met the exclusion criteria. All participants were recruited from the Department of Pediatrics in the Physician's Office Center at West Virginia University Ruby Memorial Hospital.

The mean age of the sample was 10.23 years. The sample was evenly divided by gender, with 60 boys (asthma, $N=30$; control, $N=30$ ) and 60 girls (asthma, $N=30$, control, $N=30$ ). According to physician-report, $23.3 \%$ of children in the asthma group had mildly severe asthma, $24.2 \%$ had moderately severe asthma, and $2.5 \%$ had severe asthma. The ethnic composition of the sample was 91.7\% Caucasian, 2.5\% African American, 1.7\% Hispanic American, and 4.2\% were of mixed or other races. Of the parents, 110 were mothers (asthma, $N=54$; control, $N=56$ ) and 10 were fathers (asthma, $N=6$; control, $N=4$ ). The mean age of the parents was 36.8 years. 
Forty percent of the parents completed some form of college, $38 \%$ completed high school, $10 \%$ had a four-year college degree, $5 \%$ had a graduate degree, $5 \%$ did not graduate from high school, and $2 \%$ completed some post-college education. Fifty three percent of the parents were married to the child's biological parent, $16 \%$ were divorced, $14 \%$ were single/never married, $13 \%$ were married to the child's step-parent, $3 \%$ were living with a boyfriend or girlfriend, and $1 \%$ reported being widowed.

\section{Child Measures}

The following measures were given to all children regardless of group membership. The Multidimensional Anxiety Scale for Children (MASC). The MASC (March et al., 1997) is a 39-item multidimensional measure designed to assess symptoms of anxiety disorders in children, according to diagnostic criteria from the Diagnostic and Statistical Manual of Mental Disorders ( $4^{\text {th }}$ ed. [DSM-IV] American Psychiatric Association, 1994). Items are rated on a 4point scale, ranging from "never" to "always true". The MASC consists of four factors, including Physical Symptoms, Harm Avoidance, Social Anxiety, and Separation Anxiety. The MASC has been shown to have high internal consistency and moderate concurrent validity with other measures of anxiety (March et al., 1997).

Social Phobia and Anxiety Inventory for Children (SPAI-C). The SPAI-C (Beidel et al., $1995 ; 1998)$ is a 26 -item, multidimensional measure of social anxiety in children, according to diagnostic criteria from the $D S M-I V$ (American Psychiatric Association, 1994). Items are rated on a 2-point scale and 12 of the 26 items assess anxiety experienced during interactions with familiar similar-aged peers, unfamiliar similar-aged peers, and adults. The maximum possible score on the SPAI-C is 52 and a score of 18 has been recommended to differentiate socially anxious children from non-socially anxious children (Beidel et al., 1995). The SPAI-C was 
written at a third-grade reading level and is recommended for use with children aged 8 to 14 years. The SPAI-C has been demonstrated to have excellent internal consistency, and high testretest reliability over 2-week and 10-month time periods (Beidel et al., 1995; Beidel, Turner, \& Fink,1996). The SPAI-C has the ability to successfully discriminate between typical children, children with social phobia, and children with other anxiety disorders, and has moderate concurrent validity with other measures of anxiety (Beidel et al., 1996; Morris \& Masia, 1998).

The Children's Depression Inventory (CDI). The CDI (Kovacs, 1992) is a 27-item selfreport measure, which assesses symptoms of depression in children. The CDI was written at a first grade reading level and is recommended for use with children aged 6 to 17 years. Children indicate the severity of certain feelings and thoughts from the preceding two-week period on a 0 to 2-point scale, producing a total score ranging from 0 to 54 (Smucker, Craighead, WilcoxonCraighead, \& Green, 1986). The CDI produces a global score, called Negative mood and the following four subscales: Interpersonal Problems, Ineffectiveness, Anhedonia, and Negative Self-Esteem. The CDI has the ability to successfully discriminate between typical children and children with depressive disorders, as well as between various depressive disorders (Romano \& Nelson, 1988). The CDI has been demonstrated to have an average test-retest reliability of .80 over a one-week interval and an internal consistency ranging from .70 to .86 (Del Barrio, 1993; Kovacs, 1985). The CDI has been shown to have good convergent validity with other measures of depressive behavior, including self-esteem, social adjustment, and peer relations (Strauss, Forehand, Frame, \& Smith, 1984; Kovacs, 1985).

Parental Bonding Instrument (PBI). The PBI (Parker et al., 1979) is a 25-item measure designed to assess parenting behavior and style during the child's first 16 years of life. Items are rated on a 1 (very like) to 4 (very unlike) scale. The PBI consists of two scales, Care and 
Overprotection. Items on the Care scale measure a parent's degree of tenderness and affection toward their child. Items on the Overprotection scale assess the extent to which parents exercise control over their child's independence. Consistent with scoring criteria for the PBI and the large body of literature on its use in research studies, high and low scores on the subscales are determined by median split. The following cutoff scores were used to determine parenting style, with high scores defined as those above the cutoff and low scores below the cutoff: 29 for paternal care, 32 for maternal care, 12 for maternal control, and 11 for paternal control. Four styles of parenting are categorized according to the following: a) "optimal parenting" is defined by high care and low overprotection scores, b) "neglectful parenting" is defined by low care and low overprotection scores, c) "affectionate constraint" is defined by high care and high over protection scores, d) "affectionless control" is defined by low care and high over protection scores (Parker et al., 1979).

The PBI has been demonstrated to have high internal consistency and stability over a 20year period of time (Wilhelm, Niven, Parker, \& Hadzi-Pavlovic, 2004; Mackinnon, Henderson, Scott, \& Duncan-Jones, 1989). Adequate to moderate convergent validity has been found between the PBI and other measures of attachment and parenting style (Sarason, Shearin, Pierce, \& Sarason, 1987; Parker, 1986). A modified child-version of the PBI was used for the current study to assess children's present perceptions of their parent's style of child-raising. Specifically, items were re-worded in the present tense and double-negatives were removed to be more appropriate for children's reading comprehension. This version has been shown to have moderate to good internal consistency (Greco \& Morris, 2002).

\section{Parent Measures}


Demographics Form. Parents completed a demographics form to indicate gender, age, ethnicity, and education for both themselves and their child. The parent indicated their relationship to the child (e.g., mother, father, relative), the child's other medical illnesses, current list of medications, and family history of asthma.

Functional Severity Index (FSI). The FSI (Fritz et al., 1996) is a 13-item measure designed to assess how severe parents perceive their child's asthma symptoms and functional limitations to be. Severity is rated on the following four dimensions: a) frequency of episodes, b) symptoms between episodes, c) degree of impairment throughout episodes, d) degree of impairment between episodes. The first six items (e.g., how often the child wakes during the night with coughing or wheezing) are averaged to achieve a severity score. The subsequent six items are used for qualitative/descriptive purposes.

Beck Anxiety Inventory (BAI). The BAI (Beck, Epstein, Brown, \& Steer, 1988) is a 21item self-report measure of anxiety severity for adolescents and adults. The BAI was developed as a specific measure of anxiety symptoms, separate from depressive symptoms. A 4-point scale is used to indicate how distressing common symptoms of anxiety have been during the previous week. The BAI was written to be consistent with the Diagnostic and Statistical Manual of Mental Disorders ( $3^{\text {rd }}$ edition revised [DSM-III-R] American Psychiatric Association, 1987). The maximum possible score on the BAI is 63 . The BAI has been demonstrated to have high internal consistency and moderate convergent validity with other self-report measures of anxiety symptoms (Beck et al., 1988; Osman, Kopper, Barrios, Osman, \& Wade, 1997). Test-retest reliability ranging from .75 to .83 over one-week and five-week intervals has been found for the BAI (Beck et al., 1988; De Beurs, Wilson, Chambless, Goldstein, \& Feske, 1997). The BAI has 
been shown to successfully discriminate between individuals with anxiety disorders, depressive disorders, comorbid anxiety and depression, and typical individuals (Beck et al., 1988). Social Phobia and Anxiety Inventory (SPAI). The SPAI (Turner, Beidel, Dancu, \& Stanley, 1989) is a 45 -item self-report measure designed to assess symptoms of social anxiety disorder, according to the Diagnostic and Statistical Manual of Mental Disorders $\left(3^{\text {rd }}\right.$ edition, [DSM-III] American Psychiatric Association, 1980). Cognitive, behavioral, and somatic symptoms are assessed in various situations and items are rated on a 7-point scale. The maximum possible score on the SPAI is 192. High internal consistencies have been reported for the SPAI ranging from .85 to .96 ( Osman, Barrios, Aukes, \& Osman, 1995; Turner et al., 1989). The SPAI has been shown to have test-retest reliability of .86 over a two-week period and moderate to high convergent validity with other measures of anxiety. The SPAI also has been shown to successfully discriminate between socially anxious and non-socially anxious individuals (Turner et al., 1989; Rodebaugh, Chambless, Terrill, Floyde, \& Uhde, 2000). Beck Depression Inventory - II (BDI-II). The BDI-II (Beck, Steer, \& Brown, 1996) is a 21-item multidimensional measure designed to assess symptoms of depression in adolescents and adults, consistent with diagnostic criteria from the DSM-IV (American Psychiatric Association, 1994). The BDI-II consists of two factors; the Cognitive-Affective factor contains items which target feelings of sadness, loss of interest in previously enjoyed activities, negativity, suicidal ideation, anhedonia, moodiness, and inability to make decisions. The Somatic factor contains items which target changes in sleep and appetite patterns, energy loss, difficulties focusing, and excessive tiredness (Whisman, Perez, \& Ramel, 2000). Symptom severity is rated for the previous two weeks on a 4-point scale. The maximum possible score on the BDI-II is 63, with higher scores indicative of more severe depressive symptoms. 
A cutoff score of 16 has been recommended for discriminating between individuals with and without depressed mood (Sprinkle et al., 2002). The BDI-II has been demonstrated to have high internal consistency ranging from .83 to .92 , and good convergent validity with other measures of depression ( Sprinkle et al., 2002; Storch, Roberti, \& Roth, 2004; Whisman et al., 2000). The BDI-II has been shown to successfully discriminate between individuals with depression, individuals without depression, and individuals with other psychological disorders (Beck et al., 1996). A test-retest reliability coefficient of .96 has been reported for the BDI-II over a one-week interval (Sprinkle et al., 2002).

Parent-Child Relationship Inventory (PCRI). The PCRI (Gerard, 1994) is a 78-item selfreport measure of parenting behaviors and relationship quality between parent and child. The PCRI consists of the following seven subscales: Parental Support (i.e., how much emotional and physical support the parent receives from external sources), Satisfaction with Parenting (i.e., how much the parent enjoys their role), Involvement (i.e., how much the parent takes part in activities with their child), Communication (i.e., extent to which parent talks to child about life issues), Limit Setting (i.e., consistency with discipline), Autonomy (i.e., promotion of child's independence), and Role Orientation (i.e., the degree of parenting responsibilities that the parent has). Items are rated on a 4-point scale. The PCRI has been demonstrated to have good internal consistency and test-retest reliability (Gerard, 1994). The PCRI has also been shown to have moderate to good concurrent validity with other measures of parenting behaviors (Heinze \& Grisso, 1996). For the purposes of the current study, the following subscales were analyzed: Involvement, Communication, and Autonomy.

Physician Measures 
Physician Severity Rating. Physicians indicated the child's asthma severity on a brief measure according to frequency of asthma attacks. The children's asthma was rated according to the following: (a) mild (brief, infrequent episodes with acute treatment of symptoms), (b) moderate (more frequent attacks with daily treatment), and (c) severe (frequent episodes which interfere with physical activity and continuous treatment with multiple medications). This is consistent with diagnostic guidelines proposed by the National Heart, Lung, and Blood Institute (National Institute of Health [NIH], 1997).

\section{Procedure}

Clinic physicians assisted the researcher with identifying potential candidates for the study. The researcher approached identified children and at least one of their parents in the waiting room of the Pediatric and Adolescent Group Practice at the West Virginia University Ruby Memorial Hospital, as they waited to be called for their scheduled appointment in the asthma clinic. A description of the study and participation requirements was provided to the parent and child. Participants then completed parental consent and child assent forms, as well as Health Insurance Privacy and Portability Act (HIPPA) notification forms. The parent and child then attended their scheduled appointment.

For families who provide consent and assent, the researcher escorted the parent(s) and child back to the waiting room and provided instructions for completing the self-report measures. All children were asked to read the first several items of the first scale aloud to evaluate their reading and comprehension capabilities. When necessary, the questionnaires were read to the children and their answers recorded. Twelve participants required the materials to be read to them by the research assistant. The children completed their self-report measures in the following order: $P B I, M A S C, S P A I-C$, and $C D I$. Parents will first complete the demographics 
information form, followed by the Functional Severity Index, BAI, PCRI, SPAI, and BDI-II. For children in the asthma group, physicians completed the Physician Severity Rating form at the end of each child's visit.

\section{Results}

No significant differences were found between asthma and control groups on the following demographic variables: race $(t(118)=-.512, p=.332)$, child's age $(t(118)=-.203, p=$ $.849)$, caregiver's age $(t(118)=2.18, p=.235)$, caregiver's highest level of education $(t(118)=$ $1.18, p=.537)$, and caregiver's marital status $(t(118)=-.279, p=.479)$.

Parenting Style and Group Status. A chi-square test was used to determine whether parenting style differed by group. Group status (i.e., asthma vs. control) was compared to the four categories of parenting style on the PBI (i.e., high care - low overprotection, low care - low overprotection, low care - high overprotection, and high care - high protection). This statistical method was chosen because the data are categorical. The respective parenting style categories consisted of the following number of participants: optimal (asthma, $n=22$; control, $n=21$ ), neglectful (asthma, $n=5$; control $=4$ ), affectionate restraint (asthma, $n=15$; control, $n=20$ ), affectionless control (asthma, $n=18$; control, $n=15$ ). There were no significant differences between groups on parenting style, $\left(\mathrm{X}^{2}=1.12, p=.772\right)$.

Parent-Child Relationship and Group Status. A one-way multivariate analysis of variance (MANOVA) was used to compare group status (i.e., asthma versus control) to scores on the Involvement, Communication, and Autonomy subscales of the PCRI. The independent variable was group status and the dependent variables were scores on the Involvement, Communication, and Autonomy subscale of the PCRI. There was no main effect of group status on Involvement $(F(1,118)=.404, p=.526)$, Communication $(F(1,118)=.111, p=.740)$, and 
Autonomy $(F(1,118)=1.29, p=.258)$. See Table 1 for mean scores on the PCRI and PBI subscales by group.

Anxiety and Depression Scores by Group. A MANOVA was conducted to compare the parents from the two groups (i.e., asthma and control) on total BAI, SPAI, and BDI-II scores. The independent variable was group status and the dependent variables were total scores on the BAI, SPAI, and BDI-II. There was no significant interaction between group status and scores on the $\operatorname{BAI}(F(1,118)=.077, p=.782), \operatorname{SPAI}(F(1,118)=.095, p=.758)$, and $\operatorname{BDI}-\mathrm{II}(F(1,118)$ $=3.163, p=.078)$.

A MANOVA was conducted to compare children's group status on total MASC, SPAI$\mathrm{C}$, and CDI scores. The independent variable was group status and the dependent variables were total scores on the MASC, SPAI-C, and CDI. There were no significant interactions between group status and total scores on the SPAI-C $(F(1,118)=.029, p=.864)$, or $\operatorname{CDI}(F(1,118)=$ $.029, p=.739)$. A significant interaction was found between group status and total scores on the $\operatorname{MASC}(F, 118)=6.09, p<.05)$. Children with asthma obtained significantly higher scores on the MASC $(M=50.28, S D=16.02)$ than controls $(M=43.50, S D=14.02)$.

A follow-up one-way ANOVA was conducted to examine the significant interaction between group status and MASC subscale scores. Significant interactions were found between group status and scores on the following MASC subscales: Physical Symptoms $(F(1,118)=$ $7.58, p<.05)$, Harm Avoidance $(F(1,118)=4.82, p<.05)$, and Separation Anxiety $(F(1,118)$ $=4.92, p<.05$ ). Children with asthma scored significantly higher than controls on Physical Symptoms (asthma, $M=10.85, S D=5.87$; control, $M=8.07, S D=5.18$ ), Harm Avoidance (asthma, $M=19.53, S D=4.64$; control, $M=17.62, S D=4.92$ ), and Separation Anxiety (asthma, $M=10.3, S D=5.23$; control, $M=8.33, S D=4.46)$. 
Parenting Style, Group Status, Anxiety, and Depression Scores. Physician-rated severity was included in the following analyses to be consistent with previous research (e.g., Gupta et al., 2000; Ortega et al., 2003; Vila et al., 1998). Physician rated severity and parent rated severity (i.e., FSI scores) were converted to z-scores and compared. Physician severity ratings and FSI scores were strongly correlated $(r=.89)$ and there were no significant differences between ratings. Children in the asthma group obtained an average score of 1.26 on the FSI and 1.56 on the physician severity rating forms.

See Table 2 for anxiety and depression scores by group and severity level. The small number of children with severe asthma (i.e., $\mathrm{n}=3$ ) limits the ability to conduct full analyses with all three levels of physician-rated severity (i.e., mild, moderate, and severe). Thus, children with moderate and severe asthma were combined as a single group. This resulted in 28 children with mild asthma and 32 children with moderately severe asthma. Separate multiple regression analyses were performed to examine the associations among parenting style, group status, physician-rated asthma severity, and parent's anxiety and depression scores on the children's anxiety and depression scores. Separate multiple regression analyses were conducted for each dependent variable (i.e., total scores on the MASC, SPAI-C, and CDI).

For the first regression, the independent variables were parenting style (e.g., optimal parenting), group status, physician-rated asthma severity, scores on the BAI, BDI-II, and social phobia subscale of the SPAI. The dependent variable was children's total scores on the MASC. A significant model was found, $F(6,113),=2.29, p<.05)$. See Table 3 for regression coefficients, and semipartial correlations. See Table 4 for correlations between variables. Parenting style was the only beta that emerged as significant $(\beta=.21, p<.05)$. The total model accounted for $10.8 \%$ of the variance in children's scores on the MASC $(R=.108)$. Parenting 
style uniquely accounted for $6.8 \%$ of the variance $\left(s r_{\mathrm{i}}^{2}=.040\right)$.

The Bonferroni multiple comparisons post-hoc test was chosen to further examine the association between different parenting styles and children's scores on the MASC. This test was chosen because it is a conservative approach and adjusts for the multiple comparisons. Children who reported their parents to use an affectionate restraint style of parenting scored significantly higher on the MASC $(M=53.0, p<.05)$ than those who endorsed optimal parenting style $(M=$ 41.72).

For the next regression, the same independent variables were entered and the dependent variable was children's scores on the SPAI-C. The model was not significant, $F(3,116)=1.38$, $p=.231$. Finally, a third regression was conducted using the same independent variables and children's scores on the CDI. The model was not significant, $F(3,116)=1.53, p=.176$.

\section{Discussion}

This examination of the association between parenting factors and anxiety in children with asthma, partially replicated previous research. In general, this study showed higher general anxiety scores in children with asthma, and an association between parenting style and anxiety scores with no difference between asthma and control groups. These findings are similar to Ortega et al. (2003), Ortega et al. (2004), Silove et al. (1991), and Rapee and Melville (1997). This was one of the first investigations to control for physician-rated asthma severity when addressing the association between parenting style and general anxiety in children with asthma. Asthma severity, however, was not found to explain a significant amount of variance in children's scores on the MASC, CDI, or SPAI-C. It is important to note that that the majority of children with asthma were reported to have mild or moderately severe asthma. Only three children were reported to have severe asthma. The limited number of children with severe 
asthma limits the conclusions that can be drawn regarding the association between asthma severity and children's scores on anxiety and depression measures. It may be beneficial for future studies to include large comparison groups of children with mild, moderate, and severe asthma to better understand the role that asthma severity plays in children's symptoms of anxiety and depression. Larger samples may also allow for multiple analyses comparing differences between self-reported and physician-reported asthma severity with regards to children's scores on anxiety and depression measures.

Parenting Style and Group Status. Contrary to hypotheses, parenting style on the PBI did not differ between groups. These findings are similar to those of Weil et al. (1999), and inconsistent with Klinnert et al. (1994) and Mrazek et al. (1999). It is important to note that the term "parenting" encompasses many variables and has been defined differently in previous studies. Specifically, the current study and Weil et al. (1999) are two of the only studies which focused on controlling styles of parenting that have been found to play a role in anxiety (e.g., Hudson \& Rapee, 2002). Both studies, however, did not demonstrate that overcontrolling parenting is more likely to occur in children with asthma than controls. This suggests that further large-group studies are needed to determine whether parenting style differs between children with asthma versus controls. It may be beneficial to include comparative groups of children with other chronic illnesses. Further, it may be beneficial to clarify the definition of parenting style in order to compare findings across multiple studies.

Parent-Child Relationship and Group Status. This is one of the first investigations to compare children with asthma to controls on parent-child relationship status. For the purposes of the current study, the Involvement, Communication, and Autonomy subscales of the PCRI were examined in association with group status. No significant differences were found on these 
subscales between children with asthma and controls. It is difficult to determine whether this result truly reflects no differences or methodological limitations, such as small sample size. Future studies are warranted to determine whether various aspects of the parent-child relationship differ between children with asthma and controls. This is especially important, given previous research that has shown the parent-child relationship to play a mediating role in the development of depression in children with asthma (e.g., Bleil, Ramesh, Miller, \& Wood, 2000) Anxiety and Depression Scores by Group. Inconsistent with hypotheses and previous studies (e.g., Butz \& Alexander, 1993; Weil et al., 1999), parents'scores on anxiety and depression measures did not differ significantly between groups. Parents of children with asthma were expected to obtain higher scores on the BAI, BDI, and social phobia subscale of the SPAI. Given the inconsistency between this study and previous studies, it is possible that variables specific to the sample reduced differences between parents of children with asthma and controls. There are various methodological differences between the current study and previous studies, including differences in measures of parental psychopathology. Further, previous studies may have included larger groups of children with severe asthma. It is possible that parental psychopathology is specifically related to severe childhood asthma. Future studies may benefit from examining specific differences in anxiety and depression symptoms between children with mild, moderate, and severe asthma. Future studies would benefit from the inclusion of multimethod assessments of anxiety and depression. These may include self-reports, interviews, and behavioral observations. Such methods may increase the validity of conclusions.

Consistent with previous findings (e.g., Bussing et al., 1996; Ortega et al., 2003), a significant association was found between group status and scores on the MASC, with children in the asthma group obtaining higher scores. Follow-up analyses demonstrated that children with 
asthma scored higher than controls on three of the four MASC subscales, including Physical Symptoms, Harm Avoidance, and Separation Anxiety. These findings are consistent with previous research which has demonstrated a specific association between asthma and separation anxiety (e.g., Goodwin, Messineo, Bregante, Hoven, and Kairam, 2005; Slattery et al., 2002; Ortega, Huertas, Canino, Ramirez, Rubio-Stipec, 2002; Ortega et al., 2003). Goodwin et al. (2005) hypothesized that behavioral inhibition explains the association between asthma and separation anxiety. This also would be consistent with children with asthma obtaining higher scores on the harm avoidance subscale of the MASC. It is important to note, however, that socially anxious children are also often behaviorally inhibited (e.g., Turner, Beidel, \& Wolff, 1996) and no significant association was found between group status and scores on the SPAI-C or social anxiety subscale on the MASC. Further research is warranted on the association between asthma and specific anxiety disorders. Structured diagnostic interviews for anxiety disorders in children, such as the ADIS (Silverman \& Nelles, 1988) should be used to increase the validity of findings.

Children with asthma may have obtained higher scores on the Physical Symptoms subscale of the MASC, because they are likely to experience a greater rate of physiological symptoms due to asthma. Further, questions on the Physical Symptoms subscale of the MASC (e.g., "I have pains in my chest") may overlap with symptoms experienced during an asthma episode (e.g., chest pain and restriction).

As previously mentioned, there were no significant differences between groups on SPAIC scores. No published studies were found on the specific association between social anxiety and asthma. Findings from the current study indicate that children with asthma are not more socially anxious than controls. These results should be interpreted with caution, however, as only one 
self-report measure of social anxiety was used. It is also important to note that the small number of children with severe asthma in the current study may have limited findings on the association between asthma and social anxiety scores. Previous research has demonstrated that children with severe asthma experience more activity limitations and poorer overall quality of life than children with mild to moderately severe asthma. Thus, it is important for future research to address the association between physician-rated asthma severity and symptoms of social anxiety. Self-report, parent-report, interviews, and behavioral observations should also be used to reduce the likelihood that findings are due to reporter biases.

No significant differences were found between asthma and control groups on the CDI. It is possible that the association between asthma and psychopathology in children is strongest among anxiety disorders. Recent improvements in asthma medications should also be noted. Better treatment and control of asthma symptoms may result in fewer differences between children with asthma and controls. Future studies should include measures of hospitalizations, episodes, steroid use, and comparisons of pre- and post-treatment functioning. Further research is necessary to determine how anxiety and asthma are related. Twin, observational, and longitudinal studies may shed more light on how anxiety and asthma are causally associated. Parenting Style, Group Status, Anxiety, and Depression Scores. Only one significant regression model was found. Parenting style was shown to be a significant predictor of anxiety in both children with asthma and controls, accounting for a small proportion of the variance. Follow-up analyses demonstrated that children who reported their parents to have an affectionate restraint style of parenting obtained higher scores on the MASC than children who reported optimal parenting styles. Affectionate restrained parenting consists of high levels of control and warmth (Parker et al., 1979). Previous studies have demonstrated that overcontrolling parenting 
style is predictive of children's anxiety symptoms, however, such studies have generally shown low levels of warmth to accompany high levels of control (e.g., Moore, Whaley, \& Sigman, 2004; Barrett, Fox, \& Farrell, 2005) Findings from the current study, however, demonstrated that both high levels of parental control and warmth predicted significantly higher scores on the MASC than low levels of control and high levels of warmth (i.e., optimal parenting). Various terms and measures are used to define the terms "warmth" and "parenting style" and may serve to complicate findings. Further large group studies are warranted to determine what role parental warmth plays in child anxiety.

Contrary to hypotheses, group status, parent's scores on anxiety and depression measures, and physician-rated asthma severity were not significant predictors of children's scores on the MASC, CDI, or SPAI-C. Group status was not predictive of anxiety symptoms, however a MANOVA demonstrated a significant association between group status and scores on the MASC. Consistent with previous studies, physician-rated asthma severity was not predictive of the children's self-report of their anxiety symptoms (e.g., Wamboldt et al., 1998). Vila et al. (1998) and Wamboldt et al., (1998) did, however, demonstrate that asthma severity was related to parent-report of children's anxiety symptoms. It should also be noted that the current study was conducted in an allergy and immunologist clinic. Studies have shown that specialists have better control over children's asthma symptoms than generalists (e.g., Diette et al., 2001). Thus, it is possible that the children in the study were experiencing fewer symptoms than children who see generalists for asthma control. Future studies should include groups of children from generalist and specialist clinics and should incorporate larger groups of children with each level of asthma severity, allowing for comparisons between children with mild, moderate, and severe asthma. 
Inconsistent with hypotheses and prior studies, parental scores on the anxiety and depression measures were not predictive of children's scores on anxiety and depression measures (e.g., Weil et al., 1999). This may reflect the non-clinical nature of the sample. It is important to note that studies vary in the measures and methods used to measure psychopathology, making it difficult to compare results across studies. Future studies should include comparison groups of community and clinical samples to determine how parental and child psychopathology are related.

Summary. This was one of the first studies to examine the association between parenting factors and anxiety in children with asthma. Inconsistent with hypotheses and limited previous research (e.g., Weil et al., 1999), parenting style did not differ between asthma and control groups. Further, no differences were found between groups on parent child relationship variables, including the following subscales: Involvement, Communication, and Autonomy. Consistent with hypotheses and previous research, scores on the MASC differed by group with children in the asthma group obtaining the highest scores (e.g., Goodwin et al., 2005; Ortega et al., 2003). Follow-up analyses demonstrated that children with asthma obtained significantly higher scores than controls on the following subscales of the MASC: Physical Symptoms, Harm Avoidance, and Separation Anxiety. Contrary to hypotheses, there were no significant differences between groups on the SPAI-C or CDI.

Parent's scores on the BAI, SPAI, and BDI were not significantly different between asthma and control groups, as expected. Only one significant regression model was found, with parenting style, group status, asthma severity, and parent's scores on anxiety and depression measures as the independent variables. The dependent variable was scores on the MASC. The regression model accounted for a total variance of $11 \%$. The only significant predictor was 
parenting style, accounting for about $6.7 \%$ of the variance. Inconsistent with hypotheses group status, asthma severity, and parental anxiety/depression scores were not significant predictors of children's scores on the MASC, SPAI-C, and CDI.

Limitations. Limitations of the current study should be noted. The sample size was small given the large number of variables analyzed, possibly limiting conclusions. The small sample of children with severe asthma may have specifically limited conclusions that could be drawn regarding the association between asthma severity and children's scores on anxiety and depression measures. The sample also consisted of primarily Caucasian children, representative of the local community. Future research may benefit from a multicultural focus to determine how parenting style relates to anxiety in children with asthma. This study consisted of only self-report measures of symptoms of anxiety and depression. The use of self-report measures to assess these constructs may have limited the understanding of how parenting factors relate to anxiety in children with asthma. A multi-method assessment of anxiety and depression, including parentreport, behavioral observations, and structured diagnostic interviews, would have increased the validity of findings. Finally, data collection was limited to a single community pediatric outpatient setting. It may be necessary to conduct future studies comparing clinical, community, and multiple outpatient samples to determine whether these samples differ with respect to parenting as it relates to anxiety in children with asthma.

Implications. In general, the current investigation has some implications for children with asthma. Results from the current study confirm previous research that children with asthma report higher symptoms of anxiety than children without asthma. Some suggestions for clinical application of this work include conducting early assessment and intervention work to reduce functional and developmental impairment. Such assessment should involve targeting comorbid 
anxiety symptoms or disorders and asthma in children or adolescents with family histories of such disorders. The current study did not demonstrate that parenting style plays a role in the association between anxiety and asthma. Further research is necessary to determine how anxiety and asthma are associated in order to better assess and treat children with these comorbid disorders. 


\section{References}

Achenbach, T. M., \& Edelbrock, C. (1983). Manual for the Child Behavior Checklist and Child Behavior Profile. Burlington, VT: Child Psychiatry, University of Vermont.

Akinbami, L. J., \& Schoendorf, K. C. (2002). Trends in childhood asthma: Prevalence, health care utilization, and mortality. Pediatrics, 110, 315-323.

Akinbami, L. J., Schoendorf, K. C., \& Parker, J. (2003). US childhood asthma prevalence estimates: The impact of the 1997 national health interview survey redesign. American Journal of Epidemiology, 158, 99-104.

American Psychiatric Association (1980). Diagnostic and Statistical Manual of Mental Disorders, $3^{\text {rd }}$ edition. Washington, DC: American Psychiatric Associaiton.

American Psychiatric Association (1987). Diagnostic and Statistical Manual of Mental Disorders, $3^{\text {rd }}$ edition revised. Washington, DC: American Psychiatric Association.

American Psychiatric Association (1994). Diagnostic and Statistical Manual of Mental Disorders, $4^{\text {th }}$ edition. Washington, DC: American Psychiatric Association.

Arcus, D. Biological mechanisms and personality: Evidence from shy children. Advances: The Journal of Mind - Body Health, 10, 40-49.

Barrett, P. M., Fox, T., \& Farrell, L. J. (2005). Parent-child interactions with anxious children and with their siblings: An observational study. Behaviour Change, 22, 220-235.

Beck, A. T., Epstein, N., Brown, G., \& Steer, R. A. (1988). An inventory for measuring clinical anxiety: Psychometric properties. Journal of Consulting and Clinical Psychology, 56, 893-897.

Beck, A. T., Steer, R. A., \& Brown, G. K. (1996). Manual for Beck Depression Inventory Second Edition, (BDI-II). San Antonio, TX: Psychological Corporation. 
Beck, A. T., Ward, C. H., Mendelsohn, M., Mock, J., \& Erbaugh, J. (1961). An inventory for measuring depression. Archives of General Psychiatry, 4, 561-571.

Beidel, D. C., Turner, S. M., \& Fink, C. M. (1996). Assessment of childhood social phobia: Construct, convergent, and discriminative validity of the social phobia and anxiety inventory for children (SPAI-C). Psychological Assessment, 8, 235240.

Beidel, D. C., Turner, S. M., \& Morris, T. L. (1995). A new inventory to assess childhood social anxiety and phobia: The social phobia and anxiety inventory for children. Psychological Assessment, 7, 73-79.

Beidel, D. C., Turner, S. M., \& Morris, T. L. (1998). Manual for the Social Phobia and Anxiety Inventory for Children (SPAI-C). New York: Toronto.

Bender, B. G., Annett, R. D., Ikle, D., DuHamel, T. R., Rand, C., \& Strunk, R. C. (2000). Relationship between disease and psychological adaptation in children in the childhood asthma management program and their families. Archives of Pediatrics and Adolescent Medicine, 154, 706-713.

Bleil, M. E., Ramesh, S., Miller, B. D., \& Wood, B. L. (2000). The influence of parent-child relatedness on depressive symptoms in children with asthma: Tests of moderator and mediator models. Journal of Pediatric Psychology, 25, 481-491.

Bussing, R., Burket, R. C., \& Kelleher, E. T. (1996). Prevalenc of anxiety disorders in a clinicbased sample of pediatric asthma patients. Psychosomatics, 37, 108-115.

Butz, A. M., \& Alexander, C. (1993). Anxiety in children with asthma. Journal of Asthma, 30, 199-209.

Carr, R. E. (1998). Panic disorder and asthma: Causes, effects, and research implications. 
Journal of Psychosomatic Research, 44, 43-52.

Chambers, W. J., Puig-Antich, J., Hirsch, M., Paez, P., Ambrosini, P. J., Tabrizi, M. A., et al. (1985). The assessment of affective disorders in children and adolescents by semistructured interview: Test-retest reliability of the schedule for affective disorders and schizophrenia for school-age children, present episode version. Archives of General Psychiatry, 42, 696-702.

Colp, C., Pappas, J., Moran, D., \& Lieberman, J. (1993). Variants of alpha 1-antitrypsin in Puerto Rican children with asthma. Chest, 103, 812-815.

Colp, C., Talavaera, W., Goldman, D., Green, J., Multz, A., \& Lieberman, J. (1990). Profile of bronchospastic disease in Puerto Rican patients in New York city: A possible relationship to alpha 1-antitrypsin variants. Archives of Internal Medicine, 150, 2349-2354.

Coopersmith, S. (1981). Self-esteem inventory. California: Consulting Psychologist Press.

Costello, A. J., Edelbrock, C., Kalas, R., \& Duncan, M. (1984). The NIMH Diagnostic Interview Schedule for Children (DISC): Development, reliability, and comparison between clinical and lay interviewer. Worcester, MA: University of Massachusetts Medical School.

Craske, M. G., Poulton, R., Tsao, J. C. I., \& Plotkin, D. (2001). Paths to panic disorder/agoraphobia: An exploratory analysis from age 3 to 21 in an unselected birth cohort. Journal of the American Academy of Child and Adolescent Psychiatry, 40, 556563.

Darling, N., \& Steinberg, L. (1993). Parenting style as context: An integrative model. Psychological Bulletin, 113, 487-496.

De Beurs, E., Wilson, K. A., Chambless, D. L., Goldstein, A. J., Feske, U. (1997). Convergent 
and divergent validity of the beck anxiety inventory for patients with panic disorder and agoraphobia. Depression and Anxiety, 6, 140-146).

Del Barrio, V. (1993). The children's depression inventory (CDI), 15 years later. European Journal of Psychological Assessment, 9, 51-53.

Derogatis, L. R., \& Melisaratros, N. (1983). The brief symptom inventory: An introductory report. Psychological Medicine, 13, 595-605.

Diette, G. D., Skinner, E. A., Nguyen, T. T. H., Markson, L., Clarks, B. D., \& Wu, A. W. (2001). Comparison of quality of care by specialist and generalist physicians as usual source of asthma care for children. Pediatrics, 108, 432-437.

Dohrenwend, B. S., Krasnoff, L., Askenasy, A. R., \& Dohrenwend, B. P. (1978).

Exemplification of a method for scaling life events: The PERI life events scale. Journal of Health and Social Behavior, 19, 205-229.

Dorn, L. D., Campo, J. C., Thato, S., Dahl, R. E., Lewin, D., Chandra, R., et al. (2003).

Psychological comorbidity and stress reactivity in children and adolescents with recurrent abdominal pain and anxiety disorders. Journal of the American Academy of Child and Adolescent Psychiatry, 42, 66-75.

Dumas, J. E., Serketich, W. J., \& LaFreniere, P. J. (1995). “Balance of power”: A transactional analysis of control in mother-child dyads involving socially competent, aggressive, and anxious children. Journal of Abnormal Psychology, 104, 104-113.

Engstrom, I (1999). Inflammatory bowel disease in children and adolescents: Mental health and family functioning. Journal of Pediatric Gastroenterology and Nutrition, 28, S28-S33.

Ederer, E. M. (2004). Mental health problems in young children: Self-reports and significant others as informants. Psychology Science, 46, 123-140. 
Evans, R. (1992). Asthma among minority children: A growing problem. Chest, 101, 368S-371S.

Feldman, J. M., Giardino, N. D., \& Lehrer, P. M. (2000). Asthma and panic disorder. In: D. I. Mostofsky \& D. H. Barlow (Eds.), The Management of Stress and Anxiety in Medical Disorders (pp. 220-239). Massachusetts: Allyn and Bacon.

Fritz, G. K., Yeung, A., Wamboldt, M. Z., Spirito, A., McQuaid, E. L., Klein, R. et al. (1996). Conceptual and methodologic issues in quantifying perceptual accuracy in childhood asthma. Journal of Pediatric Psychology, 21, 153-173.

Garralda, M. E., Bowman, F. M., \& Mandalia, S. (1999). Children with psychiatric disorders who are frequent attenders to primary care. European Child and Adolescent Psychiatry, $8,34-44$.

Gerard, A. B. (1994). Parent-Child Relationship Inventory (PCRI) Manual. Los Angeles, CA: Western Psychological Services.

Ginsburg, G. S., Siqueland, L., Masia-Warner, C., \& Hedtke, K. A. (2004). Anxiety disorders in children: Family matters. Cognitive and Behavioral Practice, 11, $28-43$.

Goodwin, R. D., Messineo, K., Bregante, A., Hoven, C. W., \& Kairam, P. (2005). Prevalence of probable mental disorders among pediatric asthma patients in an inner-city clinic. Journal of Asthma, 42, 643-647.

Goodwin, R. D., Pine, D. S., Hoven, C. W. (2003). Asthma and panic attacks among youth in the community. Journal of Asthma, 40, 139-145.

Goyette, C. H., Conners, C. K., \& Ulrich, R. F. (1978). Normative data on revised Conners parent teacher rating scales. Journal of Abnormal Child Psychology, 221-236.

Greco, L. A., \& Morris, T. L. (2002). Paternal child-rearing style and child social anxiety: Investigation of child perceptions and actual father behavior. Journal of Psychopathology 
and Behavioral Assessment, 24, 259-267.

Gupta, S., Mitchell, I., Gluffre, R., \& Crawford, S. (2000). Covert fears and anxiety in asthma and congenital heart disease. Child: Care, Health, and Development, 27, 335-348.

Heinze, M. C., \& Grisso, T. (1996). Review of instruments assessing parenting competencies used in child custody evaluations. Behavioral Sciences and the Law, 14, 293-313.

Hernandez-Guzman, L., \& Sancez-Sosa, J. J. (1996). Parent-child interactions predict anxiety in Mexican-American adolescents. Adolescence, 31, 955-963.

Homa, D. M., Mannino, D. M., \& Lara, M. (2000). Asthma mortality in US. Hispanics of Mexican, Puerta Rican, and heritage. Respiratory and Critical Care Medicine, 161, 504509.

Hudson, W. W. (1990). Index of Family Relations. Arizona: Walymr.

Hudson, J. L., \& Rapee, R. M. (2002). Parent-child interactions in clinically anxious children and their siblings. Journal of Clinical Child and Adolescent Psychology, 31, 548-555.

Jarjour, N. N., \& Kelly, E. A. B. (2002). Pathogenesis of asthma. The Medical Clinics of North America, 86, 925-936.

Kagan, J., Reznick, J. S., \& Snidman, N. (1987). The physiology and psychology of behavioral inhibition in children. Child Development, 58, 1459-1473.

Kagan, J., Reznick, J. S., \& Snidman, N. (1988). Biological bases of childhood shyness. Science, $240,167-171$.

Katon, W. J., Richardson, L., Lozano, P., \& McCauley, E. (2004). The relationship of asthma and anxiety disorders. Psychosomatic Medicine, 66, 349-355.

Klinnert, M. D., Mrazek, P. J., \& Mrazek, D. A. (1994). Early asthma onset: The interaction between family stressors and adaptive parenting. Psychiatry, 57, 51-61. 
Klinnert, M. D., Mrazek, D. A., \& Mrazek, P. (1992). Quality of marital relationship: A clinical rating scale. Psychiatry, 55, 132-145.

Klinnert, M. D., Nelson, H. S., Price, M. R., Adinoff, A. D., Leung, D. Y., \& Mrazek, D. A. (2001). Onset and persistence of childhood asthma: Predictors from infancy. Pediatrics, 108, E69-E72.

Kovacs, M. (1992). Manual for the Children's Depression Inventory (CDI). North Tonawanda, NY: Multi-Health Systems, Inc.

Kovacs, M. (1985). The children's depression inventory (CDI). Psychopharmacology Bulletin, 21, 995-998.

LaFreniere, P. J., Dumas, J. E., Capuano, F., \& Dubeau, D. (1992). The development and validation of the preschool socioaffective profile. Psychological Assessment, 4, 442-450.

Lish, J. D., Weissman, M. M., Adams, P. B., Hoven, C. W., \& Bird, H. (1995). Family psychiatric screening instruments for epidemiologic studies: Pilot testing and validation. Psychiatry Research, 57, 169-180.

Macdowell, A. L., \& Bacharier, L. B. (2005). Infectious triggers of asthma. Immunology and Allergy Clinics of North America, 25, 45-66.

Mackinnon, A. J., Henderson, A. S., Scott, R., \& Duncan-Jones, P. (1989). The parental bonding instrument (PBI): An epidemiological study in a general population sample. Psychological Medicine, 19, 1023-1034.

March, J. S., Parker, J. D. A., Sullivan, K., Stallings, P., \& Conners, K. (1997). The multidimensional anxiety scale for children (MASC): Factor structure, reliability, and validity. Journal of the American Academy of Child and Adolescent Psychiatry, 36, 554565. 
Martinez, F. D., \& Wright, A. L. (1995). Asthma and wheezing in the first six years of life. New England Journal of Medicine, 332, 133-138.

Masia, C. L., \& Morris, T. L. (1998). Parental factors associated with social anxiety: Methodological limitations and suggestions for integrated behavioral research. Clinical Psychology: Science and Practice, 5, 211-228.

McCubbin, H. I., Patterson, J. M., \& Wilson, L. P. (1983). Family Inventory of Life Events and Changes (FILE). St Paul: University of Minnesota, Family Social Services.

Milton, B., Whitehead, M., Holland, P., \& Hamilton, V. (2004). The social and economic consequences of childhood asthma across the lifecourse: A systematic review. Child, Care, Health, and Development, 30, 711-728.

Moore, P. S., Whaley, S. E., \& Sigman, M. E. (2004). Interactions between mothers and children: Impacts of maternal and child anxiety. Journal of Abnormal Psychology, 113, 471-476.

Morris, T. L., \& Masia, C. L. (1998). Psychometric evaluation of the social phobia and anxiety inventory for children: Concurrent validity and normative data. Journal of Clinical Child Psychology, 27, 452-458.

Mrazek, D. A., Klinnert, M., Mrazek, P. J., Brower, A., McCormick, D., Rubin, B., et al. (1999). Prediction of early-onset asthma in genetically at-risk children. Pediatric Pulmonology, 27, 85-94.

Mrazek, D. A., Klinnert, M. D., Mrazek, P., \& Macey, T. (1991). Early asthma onset: Consideration of parenting issues. Journal of the American Academy of Child and Adolescent Psychiatry, 30, 277-282.

Mrazek, D. A., Schuman, W. B., \& Klinnert, M. (1998). Early asthma onset: Risk of emotional 
and behavioral difficulties. Journal of Child Psychology and Psychiatry and Allied Disciplines, 39, 247-254.

National Center for Health Statistics (2003). Measuring childhood asthma prevalence before and after the 1997 redesign of the national health interview survey - united states. Mortality and Morbidity Weekly Report, 49, 908-911.

National Center for Health Statistics (2002). Summary health statistics for U. S. children: National health interview survey, 2002, 221, 1-87.

National Institute of Health (1997). Guidelines for the Diagnosis and Management of Asthma, 97-4051, 1-53.

Newacheck, P. W., \& Taylor, W. R. (1992). Childhood chronic illness: Prevalence, severity, and impact. American Journal of Public Health, 82, 364-371.

Ollendick, T. H. (1978). The fear survey schedule for children - revised. Unpublished manuscript, Indiana State University.

Ortega, A. N., McQuaid, E. L., Canino, G., Goodwin, R. D., \& Fritz, G. K. (2004). Comorbidity of asthma and anxiety and depression in Puerto Rican children. Psychosomatics, 45, 9399.

Ortega, A. N., McQuaid, E. L., Canino, G., Ramirez, R., Fritz, G. K., \& Klein, R. B. (2003). Association of psychiatric disorders and different indicators of asthma in island Puerto Rican children. Social Psychiatry and Psychiatric Epidemiology, 38, 220-226.

Osman, A., Barrios, F. X., Aukes, D., \& Osman, J. R. (1995). Psychometric evaluation of the social phobia and anxiety inventory in college students. Journal of Clinical Psychology, $51,235-243$.

Osman, A., Kopper, B. A., Barrios, F. A., Osman, J. R., \& Wade, T. (1997). The beck anxiety 
inventory: Reexamination of factor structure and psychometric properties. Journal of Clinical Psychology, 53, 7-14.

Parker, G. (1986). Validating an experimental measure of parental style: The use of a twin sample. Acta Psychiatrica Scandinavica, 73, 22-27.

Parker, G., Tupling, H., \& Brown, L. B. (1979). A parental bonding instrument. British Journal of Medical Psychology, 52, 1-10.

Pennebaker, J. W. (1982). The Psychology of Physical Symptoms. New York: Springer-Verlag.

Porter, B., \& O’Leary, K. D. (1980). Marital discord and childhood behavior problems. Journal of Abnormal Child Psychology, 8, 287-295.

Puig-Antich, J. H., \& Ryan, N. (1986). Schedule for Affective Disorders and Schizophrenia for School-Aged Children. Pennsylvania: Western Psychiatric Institute and Clinic.

Rapaport, M. H. (2001). Prevalence, recognition, and treatment of comorbid depression and anxiety. The Journal of Clinical Psychiatry, 62, 6-10.

Rapee, R. M., \& Melville, L. F. (1997). Recall of family factors in social phobia and panic disorder: Comparison of mother and offspring reports. Depression and Anxiety, 5, 7-11.

Reynolds, C. R., \& Richmond, B. O. (1985). Revised Children's Manifest Anxiety Scale (RCMAS). Los Angeles: Western Psychological Services.

Reznick, J. S., Kagan, J., Snidman, N., Gersten, M., Baak, K., \& Rosenberg, A. (1986). Inhibited and uninhibited children: A follow-up study. Child Development, 57, 660-680.

Rickel, A. U., \& Biasatti, L. L. Modification of the block child rearing practices report. Journal of Clinical Psychology, 38, 129-134.

Roberts, E. M. (2003). Does your child have asthma? Parent reports and medication use for pediatric asthma. Archives of Pediatric and Adolescent Medicine, 157, 449-455. 
Robin, A. L., \& Weiss, J. G. (1980). Criterion-related validity of behavioral and self-report measures of problem-solving communication skills in distressed and non-distressed parent-adolescent dyads. Behavioral Assessment, 2, 339-352.

Robins, L. N., Helzer, J. E., Croughan, J., Ratcliff, K. S. (1981). National institute of mental health diagnostic interview schedule. Its' history, characteristics, and validity. Archives of General Psychiatry, 38, 381-389.

Rodebaugh, T. L., Chambless, D. L., Terrill, D. R., Floyd, M., \& Uhde, T. (2000). Convergent, discriminant, and related validity of the social phobia and anxiety inventory. Depression and Anxiety, 11, 10-14.

Romano, B. A., \& Nelson, R. O. (1988). Discriminant and concurrent validity of measures of children's depression. Journal of Clinical Child Psychology, 1988, 17, 255-259.

Sarason, B. R., Shearin, E. N., Pierce, G. R., \& Sarason, I. G. (1987). Interrelations of social support measures: Theoretical and practical implications. Journal of Personality and Social Psychology, 52, 813-832.

Sawyer, M. G., Spurrier, N., Kennedy, D., \& Martin, J. (2001). The relationship between the quality of life of children with asthma and family functioning. Journal of Asthma, 38, 279-284.

Schluderman, E., \& Schluderman, S. (1970). Replicability of factors in children's report of parent behavior (CRPBI). Journal of Psychology, 76, 239-249.

Seligman, L. D., \& Ollendick, T. H. (1998). Comorbidity of anxiety and depression in children and adolescents: An integrative review. Clinical Child and Family Psychology Review, 1, $125-144$.

Siqueland, L., Kendall, P. C., \& Steinberg, L. (1996). Anxiety in children: Perceived family 
environments and observed family interaction. Journal of Clinical Child Psychology, 25, 225-237.

Silove, D., Parker, G., Hadzi-Pavlovic, D., Manicavasagar, V., Blaszczynski, A. (1991). Parental representations of patients with panic disorder and generalized anxiety disorder. The British Journal of Psychiatry, 159, 839-841.

Silverman, W. K., \& Nelles, W. B. (1988). Anxiety disorders interview schedule for children. Journal of the American Academy of Child and Adolescent Psychiatry, 27, 772-778.

Smucker, M. R., Craighead, E. W., Wilcoxon-Craighead, L., \& Green, B. J. (1986). Normative and reliability data for the children's depression inventory. Journal of Abnormal Child Psychology, 14, 25-39.

Spielberger, C. D., Edwards, C. D., Lushene, R. E., Mounturi, \& Platzek, D. (1973). STAIC Preliminary Manual for the State-Trait Anxiety Inventory for Children ("How I feel Questionairre"). California: Consulting Psychologists Press.

Spielberger, C. D., Gorsuch, R. L., Lushene, R., Vagg, P. R., \& Jacobs, G. A. (1983). Manual for the State-Trait Anxiety Inventory (STAI Form Y). California: Consulting Psychologists Press.

Sprinkle, S. D., Lurie, D., Insko, S. L., Atkinson, G., Jones, G. L., Logan, A. R., et al. (2002). Criterion validity, severity cutoff scores, and test-retest reliability of the beck depression inventory - II in a university counseling center sample. Journal of Consulting Psychology, 49, 381-385.

Steele, R. G., Phipps, S., \& Srivastava, D. K. (1999). Low-end specificity of childhood measures of emotional distress: Consistent effects for anxiety and depressive symptoms in a nonclinical population. Journal of Personality Assessment, 73, 276-289. 
Storch, E. A., Roberti, J. W., \& Roth, D. A. (2004). Factor structure, concurrent validity, and internal consistency of the beck depression inventory - second edition in a sample of college students. Depression and Anxiety, 19, 187-189.

Strauss, C. C., Forehand, R., Frame, C., \& Smith, K. (1984). Characteristics of children with extreme scores on the children's depression inventory. Journal of Clinical Child Psychology, 13, 227-231.

Turner, S. M., Beidel, D. C., Dancu, C. V., \& Stanley, M. A. (1989). An empirically derived inventory to measure social fears and anxiety: The Social Phobia and Anxiety Inventory. Psychological Assessment, 1, 35-40.

Turner, S. M., Beidel, D. C., \& Wolff, P. L. (1996). Is behavioral inhibition related to the anxiety disorders? Clinical Psychology Review, 16, 157-172.

Vila, G., Hayder, R., Bertrand, C., Falissard, B., De Blic, J., Mouren-Simeoni, M., et al. (2003). Psychopathology and quality of life for adolescents with asthma and their parents. Psychosomatics, 44, 319-328.

Vila, G., Nollet-Clemencon, C., De Blic, J., Mouren-Simeoni, M., \& Scheinmann, P. (1998). Asthma severity and psychopathology in a tertiary care department for children and adolescent. European Child and Adolescent Psychiatry, 7, 137-144.

Wamboldt, M. Z., Fritz, G., Mansell, A., McQuaid, E. L., \& Klein, R. B. (1998). Relationship of asthma severity and psychological problems in children. Journal of the American Academy of Child and Adolescent Psychology, 37, 943-950.

Wamboldt, M. Z., Hewitt, J. H., Schmitz, S., Wamboldt, F. S., Rasanen, M., Koskenvuo, M., et al. (2000). Familial association between allergic disorders and depression in adult Finnish twins. American Journal of Medical Genetics, 96, 146-153. 
Wamboldt, M. Z., Schmitz, S., \& Mrazek, D. (1998). Genetic association between atopy and behavioral symptoms in middle childhood. Journal of Child Psychology and Psychiatry and Allied Disciplines, 39, 1007-1016.

Weil, C. M., Wade, S. L., Bauman, L. J., Lynn, H., Mitchell, H., \& Lavigne, J. (1999). The relationship between psychosocial factors and asthma morbidity in inner-city children with asthma. Pediatrics, 104, 1274-1280.

Weinberger, D. (1991). The construct validity of the repressive coping style. In J. Singer (Ed.), Repression and Dissociation: Implications for personality Theory, Psychopathology, and Health (pp. 337-386). Illinois: University of Chicao Press.

Whisman, M. A., Perez, J. E., \& Ramel, W. (2000). Factor structure of the beck depression inventory - second edition (BDI-II) in a student sample. Journal of Clinical Psychology, $56,545-551$.

Wilhelm, K., Niven, H., Parker, G., \& Hadzi-Pavlovic, D. (2004). The stability of the parental bonding instrument over a 20-year period. Psychological Medicine, 35, 387-393. 
Table 1.

Mean PCRI and PBI Scores By Group

\begin{tabular}{|c|c|c|c|c|c|c|c|c|c|c|}
\hline & \multicolumn{2}{|c|}{ PCRI Involvement } & \multicolumn{2}{|c|}{ PCRI Autonomy } & \multicolumn{2}{|c|}{ PCRI Communication } & \multicolumn{2}{|c|}{ PBI Care } & \multicolumn{2}{|c|}{ PBI Control } \\
\hline & $M$ & $S D$ & $M$ & $S D$ & $M$ & $S D$ & $M$ & $S D$ & $M$ & $S D$ \\
\hline Asthma Group $(\mathrm{N}=60)$ & 47.12 & 4.91 & 24.77 & 4.82 & 28.12 & 3.07 & 29.13 & 2.95 & 31.88 & 4.57 \\
\hline Control Group $(\mathrm{N}=60)$ & 47.73 & 5.69 & 25.67 & 3.80 & 28.33 & 4.01 & 30.12 & 3.21 & 32.43 & 4.52 \\
\hline
\end{tabular}


Table 2 .

Mean Asthma Severity Scores and Mean Anxiety/Depression Scores by Group

\begin{tabular}{|c|c|c|c|c|c|c|}
\hline & \multicolumn{2}{|c|}{$M A S C$} & \multicolumn{2}{|c|}{$S P A I-C$} & \multicolumn{2}{|c|}{$C D I$} \\
\hline & $M$ & $S D$ & $M$ & $S D$ & $M$ & $S D$ \\
\hline Total Asthma $(\mathrm{N}=60)$ & 50.28 & 16.02 & 11.32 & 9.57 & 6.65 & 7.10 \\
\hline Mild $(\mathrm{N}=28)$ & 49.21 & 17.13 & 11.06 & 9.22 & 6.14 & 6.07 \\
\hline Moderate $(\mathrm{N}=32)$ & 51.22 & 15.19 & 11.54 & 10.01 & 7.10 & 7.97 \\
\hline Control Group $(\mathrm{N}=60)$ & 43.50 & 14.02 & 11.59 & 7.63 & 6.22 & 7.12 \\
\hline
\end{tabular}


Table 3 .

Multiple Regression of Parenting Style, Parental Anxiety/Depression Scores, Group Status, and Asthma Severity on MASC Scores

\begin{tabular}{llll}
\hline & & & \\
& $B$ & & \\
& & & \\
& & \\
PBI & $3.53^{2}$ & .213 & .041 \\
SPAI & -.068 & -.141 & .016 \\
BAI & .106 & .059 & .002 \\
BDI & .173 & .108 & .007 \\
\hline
\end{tabular}

$* p<.05$

$\mathrm{R}=.329^{\mathrm{a}}, \mathrm{R}^{2}=.109$, Adjusted $\mathrm{R}^{2}=.061$ 
Table 4.

Correlations of Parenting Style, Parental Anxiety/Depression Scores, Group Status, and Asthma Severity

\begin{tabular}{|c|c|c|c|c|c|c|c|}
\hline & $M A S C$ & Group & Severity & $P B I$ & $S P A I$ & $B A I$ & $B D I$ \\
\hline & .033 & .103 & -.095 & -.080 & -.004 & .000 & \\
\hline PBI & .159 & .090 & .003 & & .217 & .013 & -.009 \\
\hline SPAI & -.050 & .028 & .033 & .217 & & .236 & .363 \\
\hline BAI & .104 & -.025 & .103 & .013 & .236 & & .640 \\
\hline BDI & .052 & .162 & -.095 & -.009 & .363 & .640 & \\
\hline
\end{tabular}




\section{Appendix A}

\section{Demographic Form}

\section{Child Information}

Child's Gender: Male $\quad$ Female

Child's Race: $\quad$ Caucasian $\quad$ Hispanic-American African-American $\quad$ Other $\_$Asian-American

Child's Age:

Child's Date of Birth:

Child's Grade:

\section{Caregiver Information}

Your Relationship to the Child:

Mother
Other Father _ Grandparent

Your Age:

Highest level of education::

Less Than High School

High School

Some College

Four-Year College

Post-College

Graduate Degree

Please make a check in front of your marital status:

Single/Never Been Married

Divorced

Married to Child's Biological Parent

Living with Boyfriend/Girlfriend Widowed

Married to Step-Parent

1. Does the child have any illnesses other than asthma?

No _ Y Yes (please list):

2. Does the child's family have a history of asthma?

No

Yes: Please indicate:

Mother

Mother's Sibling

Mother's Parent

Father_Child's Sibling

Father's Sibling

Father's Parent 
Appendix B

Physician Severity Rating

Participant \#:

Today's Date:

Estimated Severity Score Form

\section{Rating Scale of Severity (check):}

Mild (brief, infrequent episodes with acute treatment of symptoms)

Moderate (more frequent attacks with daily treatment)

Severe (frequent episodes with continuous treatment)

\section{Physician Initials:}




\section{Appendix C}

Functional Severity Index

Participant \#:

Today's Date:

1. Some children only have episodes of asthma from time to time, and feel well between these episodes. Other children, however, may feel wheezy or tight in the chest on most days, but also suffer from more severe episodes of asthma. In the last month, how often did your child have episodes of wheezing?

Daily

A few times a week

A few times a month

Once a month

Never

Don't know

2. In the last month, how often did your child wake at night with a cough or wheezing?

Nightly

A few times a week

Less than one night/week

Only with episodes

Never

Don't know

3. In the last month, how often was your child's wheezing troublesome first thing in the morning?

Daily

A few mornings a week

Less than 1 morning a week

Only with episodes

Never

Don't know

4. In the last month, has your child had an attack that has been severe enough to limit speech to only one or two words at a time between breaths?

Yes
No
Don't know

5. In the last month, how often were your child's activities (other than sports), affected or limited by cough or wheeze or shortness of breath? 
Daily

A few times a week

A few times a month

Less than once a month

Never

Don't know

6. In the last month, how often were your child's sports activities (at school or after school)

limited or affected by cough or wheeze or shortness of breath?

Daily

A few times a week

A few times a month

Less than once a month

Never

Don't know

7. How many days has your child been in the hospital for asthma:

in the past month? ___ past year?

8. How many times has your child been in the emergency room for asthma:

in the past month?

past year?

9. How many times has your child seen a doctor for asthma:

in the past month?

past year?

10. How many days of school has your child missed due to asthma:

in the past month?

past year?

11. What medications has your child taken for asthma in the past month? (list)

12. Has your child had any oral steroids (e.g., prednisone burst, prelone):

in the past year?

ever?

13. How many days in the past month has your child had any symptoms of asthma? 